\title{
Photocatalytic activity of Ce-modified SBA-15 for the degradation of isoproturon
}

\author{
ANIL KUMAR REDDY POLICE, SRINIVAS BASAVARAJU, DURGAKUMARI VALLURI \\ and SUBRAHMANYAM MACHIRAJU* \\ Inorganic and Physical Chemistry Division, Indian Institute of Chemical Technology, Hyderabad 500607, India
}

MS received 8 March 2013; revised 28 June 2013

\begin{abstract}
Cerium (Ce)-modified SBA-15 and Al-grafted SBA-15 are prepared and compared their photocatalytic activity for isoproturon degradation. The Al-SBA-15 is prepared by postsynthetic grafting method and cerium-modified samples are prepared by the impregnation technique. All the samples are characterized by $\mathrm{X}$-ray diffraction (XRD), UV-vis diffuse reflectance spectroscopy (UV-vis DRS), scanning electron microscopy (SEM), Fourier transform infrared (FTIR) spectroscopy, X-ray photoelectron spectroscopy (XPS) and $\mathbf{N}_{2}$ adsorption/desorption analysis. The samples show well-ordered mesoporous structure and it is confirmed by XRD. The UV-vis DRS of Cemodified sample shows a red shift compared to SBA-15 and the cerium species are stabilized in +3 oxidation state at lower cerium contents. The presence of $\mathrm{Ce}^{3+}$ species is also substantiated by XPS analysis. The higher amount of $\mathrm{Ce}^{3+}$ species are accompanied by oxygen vacancies which are formed due to the contact of ceria with the support. The $\mathrm{N}_{2}$ adsorption/desorption analysis of the samples show type-IV isotherms characteristic of mesoporous materials. Photocatalytic activity evaluation studies are made on all the samples for the degradation of isoproturon. Among them, 0.3 (wt \%) Ce-modified Al-SBA-15 catalyst has shown a maximum activity in comparison with Ce-modified SBA-15. The better activity is attributed to the synergistic effect of mesoporosity and the presence of $\mathrm{Ce}^{3+}$ species along with oxygen vacancies.
\end{abstract}

Keywords. Cerium; SBA-15; photocatalytic degradation; isoproturon.

\section{Introduction}

Photocatalytic processes are found to be active in the treatment of wastewater for the destruction of several organic pollutants. ${ }^{1,2}$ Heterogeneous mediated photocatalysis has gained considerable interest for the treatment of wastewater. Generally, semiconductor oxides like $\mathrm{TiO}_{2}, \mathrm{ZnO}, \mathrm{Bi}_{2} \mathrm{O}_{3}$, etc. are employed as photocatalysts with and without supported material. ${ }^{3-11}$ Porous material such as ordered mesoporous silica is widely used as support in catalyst preparations due to their high thermal and chemical stability, as well as tunable pore-size and specific surface area. In this investigation, SBA-15 has been chosen as a support as it is used in many catalytic reactions owing to its high surface area and larger pore diameter. These support materials with various transition metals are used as heterogeneous catalysts for many organic transformations. ${ }^{12-14}$ In recent times, attention has been paid to the combination of the rare earth metals with the mesoporous materials in which the rare earth metals are used as the active catalyst component. ${ }^{15-17}$ Ceria is one of the most reactive rare earth metal oxide and it is having growing importance due to its chemical versatility in adjusting valence states $(+3$ and +4$)$ resulting in the generation of oxygen vacancies. These properties of ceria

\footnotetext{
*Author for correspondence (subrahmanyam @iict.res.in)
}

are crucial for the potential application including fast ion conductors, oxygen storage capacitors, catalysts, UV blockers, polishing materials and electrolytes for solid oxide fuel cells. $\mathrm{CeO}_{2}$ or $\mathrm{CeO}_{2}$-based materials have also been found to be very important under environmental protection materials family. In particular, supported $\mathrm{CeO}_{2}$ and $\mathrm{CeO}_{2}$-based mixed oxides are effective catalysts for the oxidation of different hydrocarbons and for the removal of organics from polluted water. $^{7,8,18}$ Existence of different sites of cerium ions and capability of one-electron oxidations, oxygen storage/release properties made the cerium containing materials important for many catalytic reactions like oxidation of $\mathrm{CO}^{19}$ watergas shift reaction ${ }^{20}$ elimination of $\mathrm{CO}$ and $\mathrm{NO}_{x}$ contaminants from automotive exhaust gases and combustion reaction of hydrocarbons. ${ }^{21}$ In this study, Ce-SBA-15 and Ce-Al-SBA15 are prepared and their performance towards photocatalytic degradation of isoproturon in aqueous solution is evaluated.

\section{Experimental}

\subsection{Chemicals and materials}

Isoproturon (analytical standard), Pluronic P123 (Poly(ethylene glycol)-block-poly(propylene glycol)-block-poly(ethylene glycol)), cetyltrimethyl ammonium bromide (CTMABr), tetraethyl orthosilicate (TEOS) and aluminum isopropoxide 
$\mathrm{Al}\left(\mathrm{OC}_{3} \mathrm{H}_{7}\right)_{3}$ were obtained from Sigma-Aldrich (India). Ammonium cerium (IV) nitrate $\left(\mathrm{NH}_{4}\right)_{2} \mathrm{Ce}\left(\mathrm{NO}_{3}\right)_{6}$ was purchased from Merck (India). HCl, ethanol, 1-propanol and $\mathrm{KBr}$ were procured from Rankem (India).

\subsection{Preparation of Al-SBA-15}

SBA-15 was prepared by procedure adopted by Zhao et $\mathrm{al}^{22}$ using tri-block copolymer (Pluronic P123) template. Aluminum was introduced into the SBA-15 via post-synthetic alumination using a grafting procedure to obtain Al-SBA-15. The procedure adopted for the grafting method has been reported elsewhere. ${ }^{23}$ Aluminum isopropoxide ( $70 \mathrm{wt} \%$ solution in 1-propanol) was used as the aluminum source, and absolute ethanol was used as the solvent. SBA-15 was made slurry in ethanol containing aluminum isopropoxide for $8 \mathrm{~h}$ at room temperature. The filtered material was then washed with ethanol and the solid was dried in air at room temperature and calcined at $823 \mathrm{~K}$ for $5 \mathrm{~h}$. The amount of aluminum was added such that the atomic ratio of $\mathrm{Si}$ to $\mathrm{Al}$ would be 40 and this material now referred as Al-SBA-15.

\subsection{Preparation of Ce-SBA-15 and Ce-Al-SBA-15}

Ce-modified SBA-15 sample was prepared by the impregnation method. Required amount of ammonium cerium (IV) nitrate was dissolved in deionized water and added $0.5 \mathrm{~g}$ SBA-15. The mixture was kept under stirring with constant slow heating till the excess water was evaporated. The samples were oven dried at $373 \mathrm{~K}$ overnight and calcined at 723 $\mathrm{K}$ for $5 \mathrm{~h}$ with a temperature ramping of $2 \mathrm{~K} \mathrm{~min}^{-1}$. Cerium (wt\%) content over SBA-15 was maintained to get 0.1, $0.3,0.6,1.0$ loaded samples. The same procedure was followed for the preparation of Ce-Al-SBA-15 samples using $0.1,0.3,0.6,1.0$ cerium (wt $\%$ ) over Al-SBA-15 support material.

\subsection{Catalyst characterization}

X-ray photoelectron spectroscopy (XPS) spectra were recorded on a KRATOS AXIS 165 equipped with $\mathrm{MgK} \alpha$ radiation (1253.6 eV) at $75 \mathrm{~W}$ apparatus using $\mathrm{MgK} \alpha$ anode and a hemispherical analyzer, connected to a five-channel detector. The analysis was performed at room temperature. Prior to the analysis, the samples were evacuated at high vacuum and then introduced into the analysis chamber. The $\mathrm{C} 1 \mathrm{~s}$ line was used as an internal standard for the normalization of binding energies.

Powder X-ray diffraction (XRD) patterns were recorded on a Rigaku diffractometer using $\mathrm{CuK} \alpha$ radiation $(0.1540 \mathrm{~nm})$, operated at $40 \mathrm{kV}$ and $40 \mathrm{~mA}$.

Surface properties of the catalysts were measured by $\mathrm{N}_{2}$ adsorption in Autosorb 1C Quantachrome physical adsorption apparatus. The specific surface area and pore volume of the samples were calculated by applying Brunauer-EmmettTeller (BET) and Barrett-Joyner-Halenda (BJH) methods, respectively.

UV-vis DRS measurements were performed over the wavelength range 200-800 $\mathrm{nm}$ using a GBC UV-Visible Cintra $10_{\mathrm{e}}$ spectrometer with an integration sphere diffuse reflectance attachment. Barium sulfate was used as standard for recording the spectra.

Fourier transform infrared (FTIR) spectra of the catalysts were recorded on a Nicolet 740 FTIR spectrometer (USA) using $\mathrm{KBr}$ self-supported pellet technique in the frequency range of $400-4000 \mathrm{~cm}^{-1}$.

For scanning electron microscopy (SEM) analysis, samples were mounted on an aluminum support using a double adhesive tape, coated with gold in HUS-SGB vacuum coating unit and observed in Hitachi S-520 SEM unit.

\subsection{Photocatalytic experiments}

Isoproturon solution $\left(1.14 \times 10^{-4} \mathrm{M}\right)$ was always freshly prepared by dissolving the required herbicide in deionized water. Prior to light experiments, dark (adsorption) experiments are carried out for monitoring the adsorption extent of the herbicide on the catalyst. For photoexperiments, $50 \mathrm{ml}$ isoproturon solution was taken in a quartz reactor along with $50 \mathrm{mg}$ of the added catalyst $\left(1 \mathrm{~g} \mathrm{l}^{-1}\right)$. The solution was illuminated under $250 \mathrm{~W}$ Mercury lamp.

\subsection{Analysis}

The isoproturon degradation was monitored by Shimadzu SPD-20A HPLC using C-18 phenomenex reverse phase column $\left(250 \times 4.6 \mathrm{~mm}^{2}-5 \mu \mathrm{m}\right)$ with acetonitrile/water $(50 / 50$

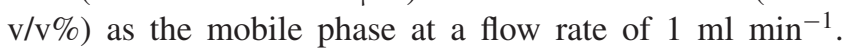
The wavelength of the LC detector was set at $254 \mathrm{~nm}$ for the detection of isoproturon. The samples collected at regular intervals are filtered through millipore microsyringe filters $(0.2 \mu \mathrm{m})$.

\section{Results and discussion}

\subsection{Characterization}

3.1a XRD: The high-angle XRD patterns of SBA-15 and Al-SBA-15 samples are shown in figure 1A. The wideangle patterns show a broad diffraction peak at $2 \theta=23^{\circ}$, which is of amorphous silica. It is seen that there are no diffraction lines due to crystalline $\mathrm{Al}_{2} \mathrm{O}_{3}$ reflections in AlSBA-15 sample. The low-angle XRD patterns of SBA-15 and Al-SBA-15 are shown in figure 1B. Low-angle wellresolved diffraction peaks that can be indexed as (100), (110) and (200) reflections are indicating the mesoporosity of the prepared materials. The diffraction peaks are related to long-range 2D hexagonal ordering in the $P 6 \mathrm{~mm}$ space group. Furthermore, the appearance of the same peaks in 

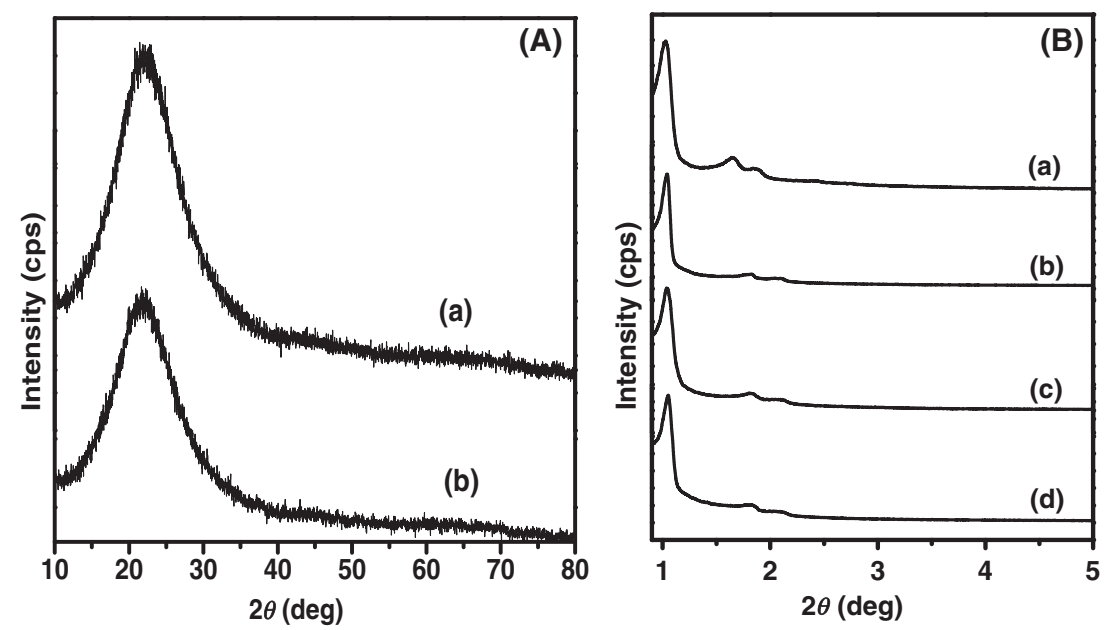

Figure 1. (A) High-angle XRD of (a) SBA-15 and (b) Al-SBA-15. (B) Low-angle XRD of (a) SBA-15, (b) 0.3 (wt \%) Ce-SBA-15, (c) Al-SBA-15 and (d) 0.3 (wt $\%$ ) Ce-Al-SBA-15.

the cerium-modified SBA-15 and Al-SBA-15 catalysts suggest that the hexagonal array of parent samples are retained after incorporation of the cerium metal. However, the diffraction intensity of (110) and (200) planes decreased with cerium loading. This can be illustrated to a slight decrease of the mesoporosity due to the pore-filling effect of $\mathrm{CeO}_{2}$ particles.

3.1b $\mathrm{N}_{2}$ adsorption/desorption analysis: In order to find out the effect of cerium modification on the surface area and porosity of the SBA-15 samples, $\mathrm{N}_{2}$ adsorption studies are employed for the bare SBA-15, Al-SBA-15 as well as Cemodified samples. The $\mathrm{N}_{2}$ adsorption/desorption isotherms of the samples shown in figure 2 are of type IV with a H1 type hysteresis loop. Three different regions can be seen on these isotherm plots: (i) a linear region due to monolayermultilayer adsorption in mesopores; (ii) a steep region due to capillary condensation within these mesopores; (iii) a second linear region due to multilayer formation on the external surface of the grains. SBA-15, Al-SBA-15 and the corresponding Ce-modified samples show a hysteresis loop. For the Ce-modified samples, the shape of the hysteresis closely resembles that of the parent SBA-15 sample. The pore volume, pore size and surface area of the samples are provided in table 1. A small decrease in the surface area for the ceriummodified samples may be due to the formation of $\mathrm{CeO}_{2}$ nanocrystals within the mesopores of SBA- 15 .

3.1c SEM-energy-dispersive X-ray analysis (EDAX): The surface morphology of $0.3 \mathrm{wt} \%$ Ce containing SBA-15 and Al-SBA-15 samples are studied by SEM and the corresponding micrographs are presented in figure 3. EDAX data of 0.3 and $1.0 \mathrm{wt} \% \mathrm{Ce}-\mathrm{Al}-\mathrm{SBA}-15$ are provided in table 2 . Both the samples have $\mathrm{Si} / \mathrm{Al}$ ratios higher than the actual

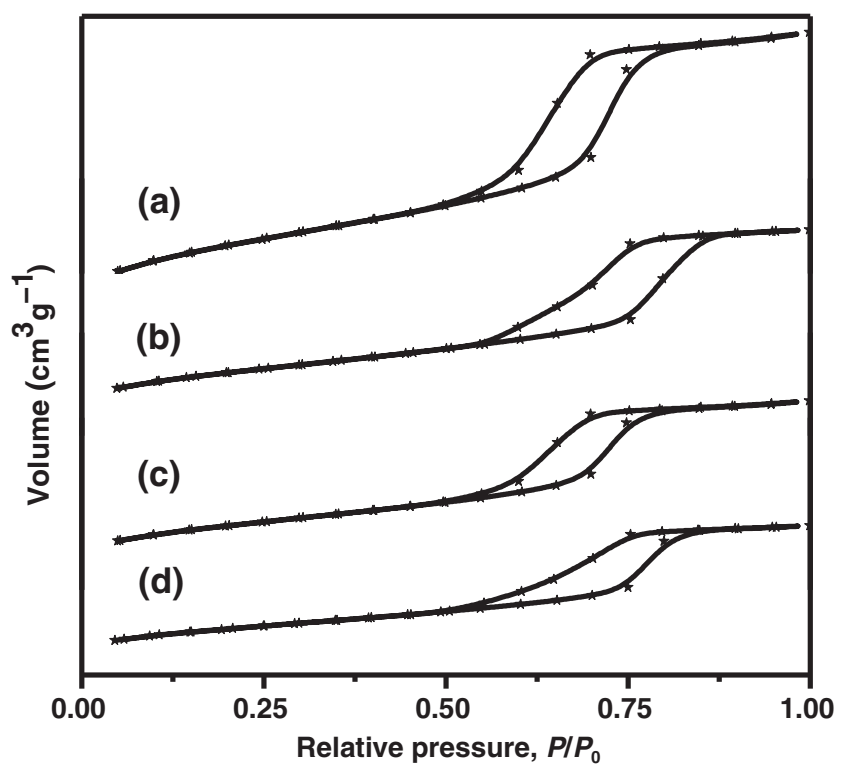

Figure 2. $\mathrm{N}_{2}$ adsorption/desorption isotherms of (a) SBA-15, (b) Al-SBA-15, (c) 0.3 (wt $\%$ ) Ce-SBA-15 and (d) 0.3 (wt $\%$ ) Ce-Al-SBA-15.

Table 1. Physicochemical properties of SBA-15, Al-SBA-15 and their cerium-modified materials.

\begin{tabular}{lcccc}
\hline & \multicolumn{4}{c}{ Surface area Pore diameter } \\
Sl. no. & Sample volume & $\left(\mathrm{m}^{2} \mathrm{~g}^{-1}\right)$ & $(\mathrm{nm})$ & $\left(\mathrm{cm}^{3} \mathrm{~g}^{-1}\right)$ \\
\hline 1 & SBA-15 & 715.32 & 6.13 & 0.98 \\
2 & Al-SBA-15 & 692.58 & 6.05 & 0.92 \\
3 & $0.3 \mathrm{wt} \%$ & 680.41 & 5.95 & 0.86 \\
& Ce-SBA-15 & & & \\
4 & 0.3 wt\% & 663.70 & 5.85 & 0.82 \\
\multicolumn{4}{c}{ Ce-Al-SBA-15 } \\
\end{tabular}




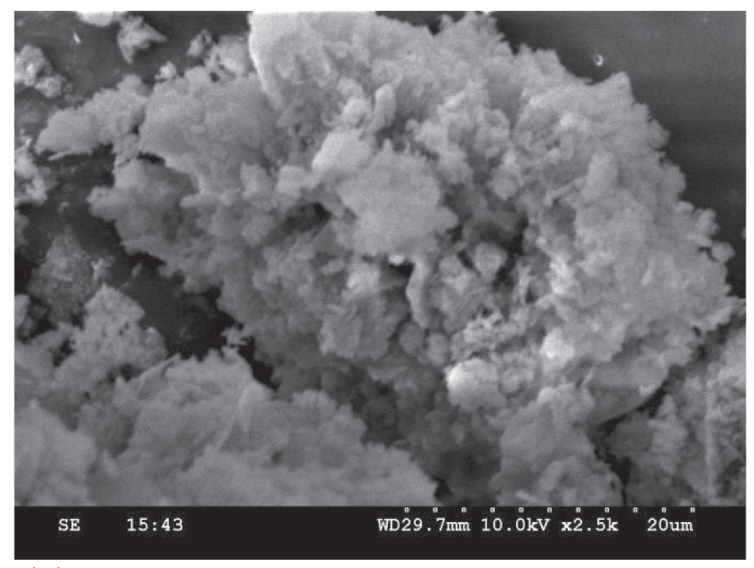

(a)

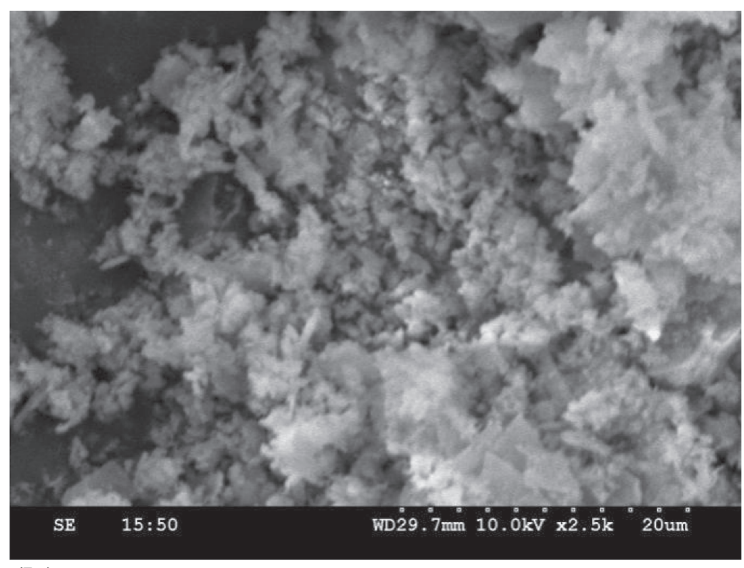

(b)

Figure 3. SEM images of (a) 0.3 (wt $\%$ ) Ce-SBA-15 and (b) 0.3 (wt $\%$ ) Ce-Al-SBA-15.

Table 2. Elemental analysis of Ce-Al-SBA-15.

\begin{tabular}{|c|c|c|}
\hline \multirow[b]{2}{*}{ Element } & \multicolumn{2}{|c|}{ Atomic $\%$ by EDAX } \\
\hline & $\overline{0.3 \mathrm{wt} \% \mathrm{Ce}-\mathrm{Al}-\mathrm{SBA}-15}$ & $1.0 \mathrm{wt} \% \mathrm{Ce}-\mathrm{Al}-\mathrm{SBA}-15$ \\
\hline $\mathrm{Si}$ & 30.10 & 29.11 \\
\hline $\mathrm{Al}$ & 0.28 & 0.21 \\
\hline $\mathrm{Ce}$ & 0.10 & 0.17 \\
\hline
\end{tabular}

amount $(\mathrm{Si} / \mathrm{Al}=40)$. The increase in $\mathrm{Si} / \mathrm{Al}$ ratio suggests that the aluminum present on the surface of the material is less than the actual amount of added aluminum. These results describe that small amount of $\mathrm{Al}$ is either entered into the framework of silica or exists in the mesopores of SBA-15.

3.1d UV-vis diffuse reflectance spectroscopy (UV-vis DRS): $\mathrm{UV}-\mathrm{vis}$ DRS measrements evidences the charge transfer processes and electronic states of the species. The DRS of cerium-modified SBA-15 and Al-SBA-15 catalysts are provided in figure 4 . The cerium-modified samples exhibit three characteristic bands at 250, 300, and $350 \mathrm{~nm}$ corresponding to $\mathrm{O}^{2-}$ to $\mathrm{Ce}^{3+}, \mathrm{O}^{2-}$ to $\mathrm{Ce}^{4+}$ charge transfer and interband transitions, respectively. ${ }^{24}$ The former band is observed because of the oxygen defects formed in ceria due to the interaction of ceria with the support SBA-15 or Al-SBA-15. The 0.1 and 0.3 wt $\%$ Ce-modified samples show more intensity of the former band than the later one. However, with the increase in cerium content the intensity of $\mathrm{O}^{2-}$ to $\mathrm{Ce}^{3+}$ charge transfer band is suppressed and $\mathrm{O}^{2-}$ to $\mathrm{Ce}^{4+}$ charge transfer band is increased and the band is shifted towards the bulk ceria. Although, the same pattern is observed for both Ce-SBA-15 and Ce-Al-SBA-15 samples the presence of more number of $\mathrm{Ce}^{3+}$ species are observed for Ce-Al-SBA-15 samples compared to Ce-SBA-15 sample. This observation is further confirmed in the XPS data provided.

3.1e FTIR: FTIR spectra of the samples are provided in figure 5. The bands at 1085 and $802 \mathrm{~cm}^{-1}$ are assigned to asymmetrical and symmetrical stretching vibrations of $\mathrm{Si}-$ $\mathrm{O}-\mathrm{Si}$ and tetrahedron $\mathrm{Si}-\mathrm{O}$ groups, respectively. The band at $965 \mathrm{~cm}^{-1}$ is caused by the $\mathrm{Si}-\mathrm{O}$ stretching vibrations of $\mathrm{Si}-\mathrm{OH}$ group present in the framework of SBA-15. In general, the IR weak characteristic band at $971 \mathrm{~cm}^{-1}$ for $V_{\text {as }}$ (Si-O-Ce) overlapped with band at $965 \mathrm{~cm}^{-1}$ for $\mathrm{Si}-\mathrm{OH}$ group. Hence, it is difficult to distinguish the effect of cerium loading on the structure of SBA-15. However, the increase in the intensity of peaks at 802 and $970 \mathrm{~cm}^{-1}$ with cerium amount suggests that cerium atoms are in interaction with the support SBA-15. To confirm this, we study the influence of cerium content on the nature of $\mathrm{OH}$-groups in Ce-SBA samples at $3000-3800 \mathrm{~cm}^{-1}$ range (the $\mathrm{O}-\mathrm{H}$ stretching region). Three types of bands at 3240,3450 and $3620 \mathrm{~cm}^{-1}$ are observed in IR spectra of all the samples. The band at $3620 \mathrm{~cm}^{-1}$ is attributed to the stretching vibration of isolated silanol groups and the band $3450 \mathrm{~cm}^{-1}$ is likely ascribed to the isolated silanol groups that slightly interact with the walls of SBA-15. The band $3240 \mathrm{~cm}^{-1}$ is attributed to the stretching vibration of hydrogen bonded $\mathrm{Si}-\mathrm{OH}$ and $\mathrm{Ce}-\mathrm{OH}$ groups. The increase in intensity of these bands with cerium loading confirms that more number of $\mathrm{OH}$ groups available on the surface of catalysts which are responsible for the photocatalytic oxidation reaction. ${ }^{25,26}$

3.1f XPS: XPS has been utilized to obtain information about the chemical composition of the surface of the material. The core level spectra of the cerium-modified samples are shown in figure $6 \mathrm{~A}$ and $\mathrm{B}$ corresponding to $\mathrm{Ce} 3 d$ and $\mathrm{O} 1 s$, respectively. The Ce $3 d$ spectrum is composed of five spin-orbit doublets due to two multiplets, $3 / 2(u)$ and $5 / 2$ $(v)$. Here, $v / u, v^{\prime \prime} / u^{\prime \prime}$, and $v^{\prime \prime \prime} / u^{\prime \prime \prime}$ are attributed to $\mathrm{Ce}^{4+}: v / u$ and $v^{\prime \prime} / u^{\prime \prime}$ are due to a mixture of $(5 d 6 s)^{0} 4 f^{2} \mathrm{O} 2 p^{4}$ and $(5 d$ $6 s)^{0} 4 f^{1} \mathrm{O} 2 p^{5}$ configurations, and $v^{\prime \prime \prime} / u^{\prime \prime \prime}$ is due to the $(5 d$ $6 s)^{0} 4 f^{0} \mathrm{O} 2 p^{6}$ final state. While, $v_{0} / u_{0}$ and $v^{\prime} / u^{\prime}$ are due to $(5 d 6 s)^{0} 4 f^{2} \mathrm{O} 2 p^{5}$ and $(5 d 6 s)^{0} 4 f^{1} \mathrm{O} 2 p^{6}$ corresponding to $\mathrm{Ce}^{3+}$. A significant increase in the $u_{0} / v_{0}$ and $u^{\prime} / v^{\prime}$ with simultaneous decrease in the $u / v, u^{\prime \prime} / v^{\prime \prime}$ and $u^{\prime \prime \prime} / v^{\prime \prime \prime}$ peak intensities 

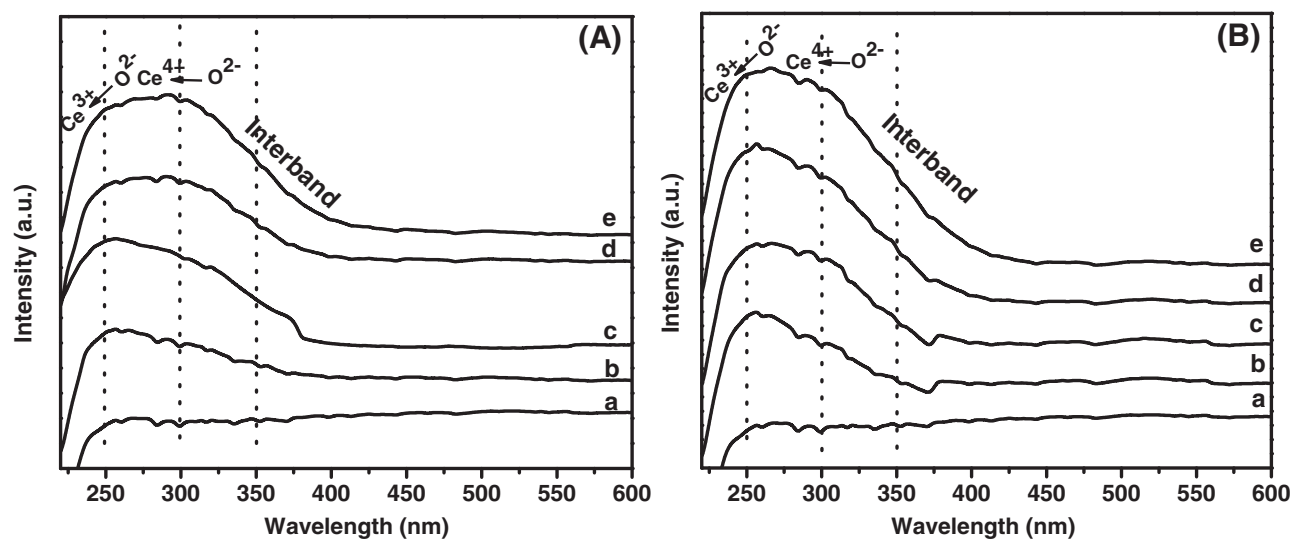

Figure 4. (A) UV-vis DRS of (a) SBA-15 and cerium, (b) 0.1 , (c) 0.3 , (d) 0.6 and (e) 1.0 (wt $\%$ ) modified SBA-15. (B) (a) Al-SBA-15 and cerium, (b) 0.1, (c) 0.3, (d) 0.6 and (e) 1.0 (wt \%) modified Al-SBA-15.

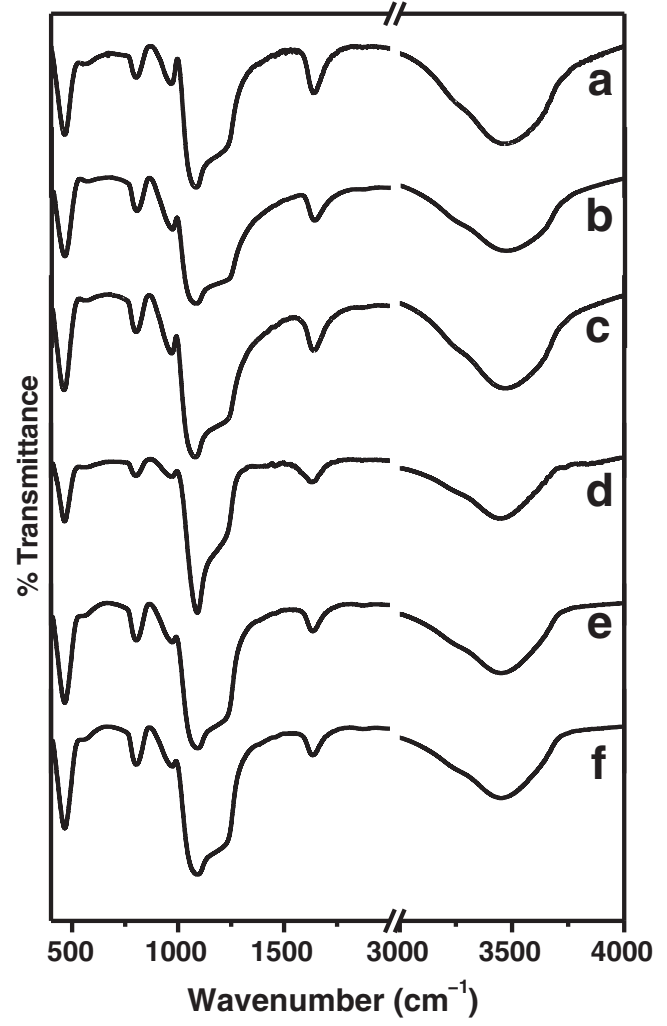

Figure 5. FTIR spectra of (a) SBA-15, (b) 0.3 (wt $\%$ ) Ce-SBA15 , (c) 1.0 (wt $\%)$ Ce-SBA-15, (d) Al-SBA-15, (e) 0.3 (wt $\%)$ Ce-Al-SBA-15 and (f) 1.0 (wt $\%$ ) Ce-Al-SBA-15.

is observed for $0.3 \mathrm{wt} \% \mathrm{Ce}-\mathrm{SBA}-15$ compared to $1.0 \mathrm{wt} \%$ cerium supported SBA-15. Therefore, an increase in $\mathrm{Ce}^{3+}$ amount can be noted for $0.3 \mathrm{wt} \%$ cerium supported SBA15 sample. Interestingly, for $0.3 \mathrm{wt} \% \mathrm{Ce}-\mathrm{Al}-\mathrm{SBA}-15$ only peaks corresponding to $\mathrm{Ce}^{3+}$ are observed and no characteristic peaks of $\mathrm{Ce}^{4+}$ are noted. This might be due to the fact that at lower loadings, cerium interacted with the support mainly present as $\mathrm{Ce}^{3+}$. This illustrates the perturbation of the electronic structure of the Ce ion brought out by a change
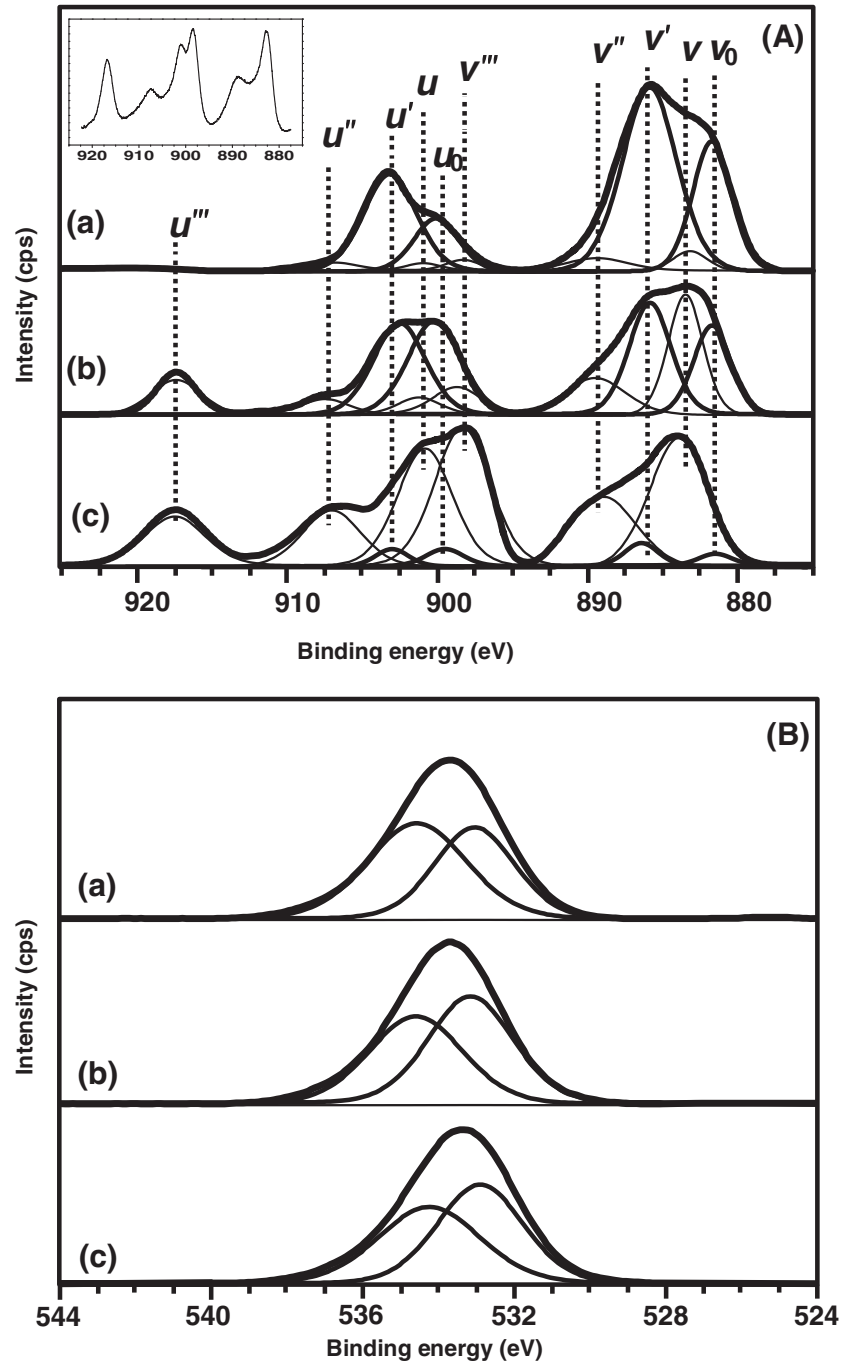

Figure 6. (A) Ce $3 d$ XPS of (a) 0.3 (wt $\%$ ) Ce-Al-SBA-15, (b) 0.3 (wt $\%$ ) Ce-SBA-15 and (c) 1.0 (wt $\%$ ) Ce-SBA-15, $\mathrm{CeO}_{2}$ (inset). (B) O $1 \mathrm{~s}$ XPS of (a) 0.3 (wt $\%$ ) Ce-Al-SBA-15, (b) 0.3 (wt $\%$ ) Ce-SBA-15 and (c) 1.0 (wt $\%$ ) Ce-SBA-15. 
in the coordination of the $\mathrm{Ce}$ and oxygen ligands when ceria is in contact with the support.

The $\mathrm{O} 1 s$ XP spectrum of the samples is shown in figure $6 \mathrm{~B}$. The $\mathrm{O} 1 s$ core level peak is mainly composed of two characteristic peaks. The first peak at a lower binding energy of $533.0 \pm 0.6 \mathrm{eV}$ is attributed to lattice oxygen of silica. Appearance of the peak at higher binding energy at $534.5 \pm 0.3 \mathrm{eV}$ corresponds to mixed contribution from oxygen defects and surface hydroxyl groups at the surface. The hydroxyl groups are also confirmed from the FTIR study. Existence, of more number of oxygen vacancies on the surface permits more amounts of chemisorbed $\mathrm{OH}$ groups on the surface which are very crucial in the photocatalytic oxidation of pollutant molecules on the surface of the catalyst. ${ }^{24,27}$

\subsection{Photocatalytic activity studies}

The photocatalytic activities of Ce-modified SBA-15 and AlSBA-15 catalysts are shown in figures 7 and 8, respectively. The catalyst containing $0.3 \mathrm{wt} \%$ cerium showed good photocatalytic activity. The photocatalytic activity of Ce-modified SBA-15 sample with increase of cerium loading found to have a decrease in activity (figure 7). A sharp decrease in the photocatalytic activity of $1.0 \mathrm{wt} \%$ cerium Al-SBA-15 may be due to the formation of agglomerated cerium crystallites that behaves as bulk ceria. This is substantiated by the XPS of $1.0 \mathrm{wt} \% \mathrm{Ce}-\mathrm{Al}-\mathrm{SBA}-15$ that shows spectra similar to bulk ceria (inset figure 6A). The $0.3 \mathrm{wt} \%$ Ce-SBA-15 sample contains most of the cerium species in +3 oxidation sate. This might be the reason for high photocatalytic activity of cerium-modified samples at lower loadings. The same was observed in the case of cerium-modified Al-SBA-15 sample (figure 8).

The comparison of photocatalytic activities of SBA-15, Ce-modified support and $\mathrm{CeO}_{2}$ are shown in figure 9. Among

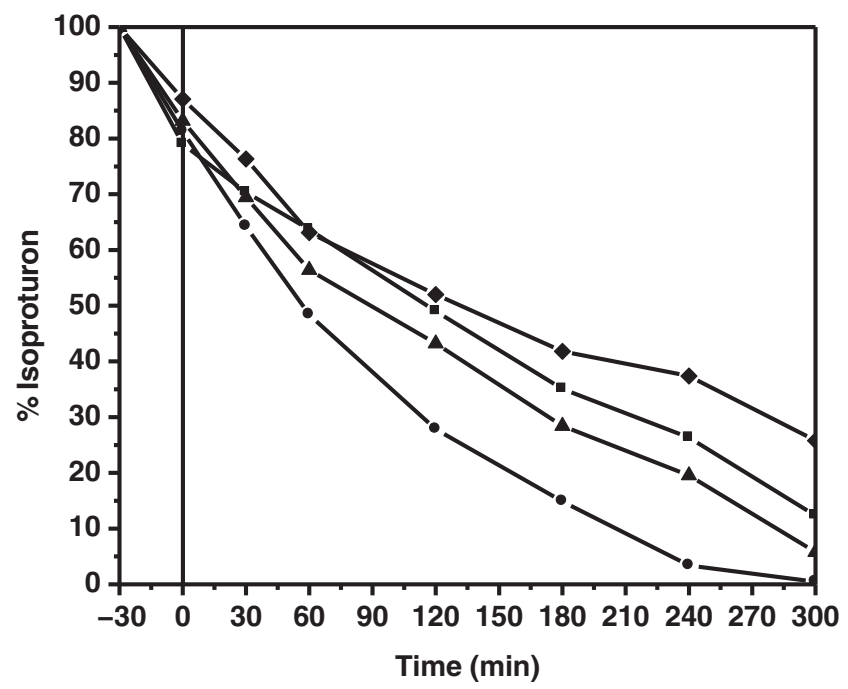

Figure 7. Photocatalytic activity of cerium $(\bullet) 0.1,(\bullet) 0.3,(\boldsymbol{\Delta})$ 0.6 , (ם) 1.0 (wt \%) loaded SBA-15 for the degradation isoproturon. all the catalysts, 0.3 wt $\%$ Ce-Al-SBA-15 has shown better activity. The enhanced photocatalytic activity of Ce-Al-SBA-15 is due to highly dispersed and interacted nano-sized ceria particles on the support. Also they show oxygen vacancies and establish a strong interaction with the support wherein, cerium is in $\mathrm{Ce}^{3+}$ form. Dispersion of ceria over alumina containing SBA-15 would permit in improving the redox performance of ceria. Due to dispersion, the close contact between the ceria and the alumina may facilitate the formation of cerium aluminum composite. This formation is generally expected to affect the $\mathrm{Ce}^{3+}$ and $\mathrm{Ce}^{4+}$ species composition as it fixes a single oxidation state, i.e., $\mathrm{Ce}^{3+}$. However, in high cerium loaded samples the features

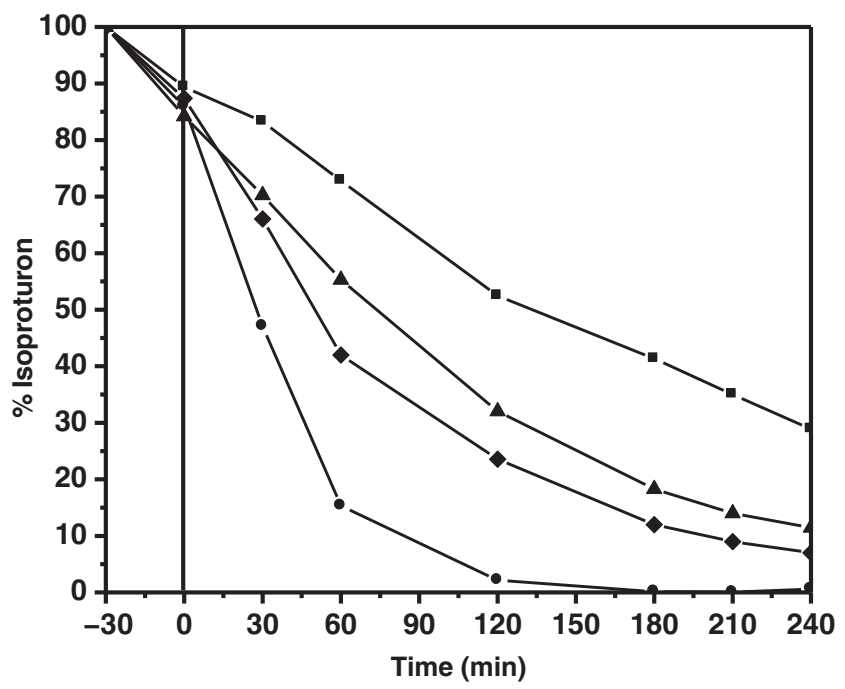

Figure 8. Photocatalytic activity of cerium $(\bullet) 0.1,(\bullet) 0.3$,

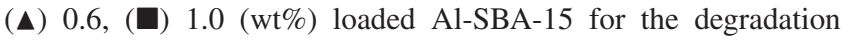
isoproturon.

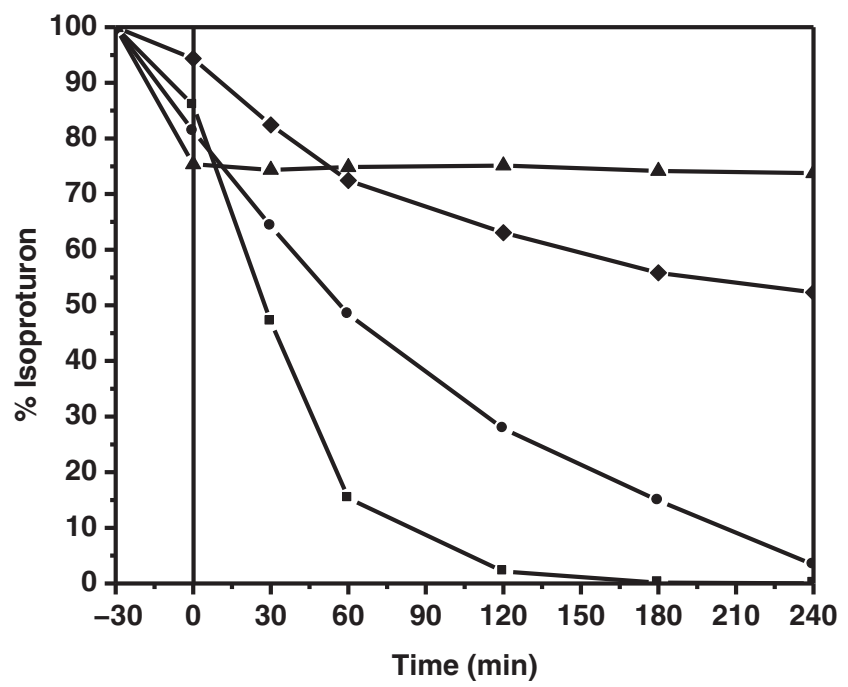

Figure 9. Photocatalytic activity comparison of (4) SBA-15, (•) 0.3 (wt $\%$ ) Ce-SBA-15, (ם) 0.3 (wt $\%$ ) Ce-Al-SBA-15 and ( ) $\mathrm{CeO}_{2}$ for the degradation of isoproturon. 


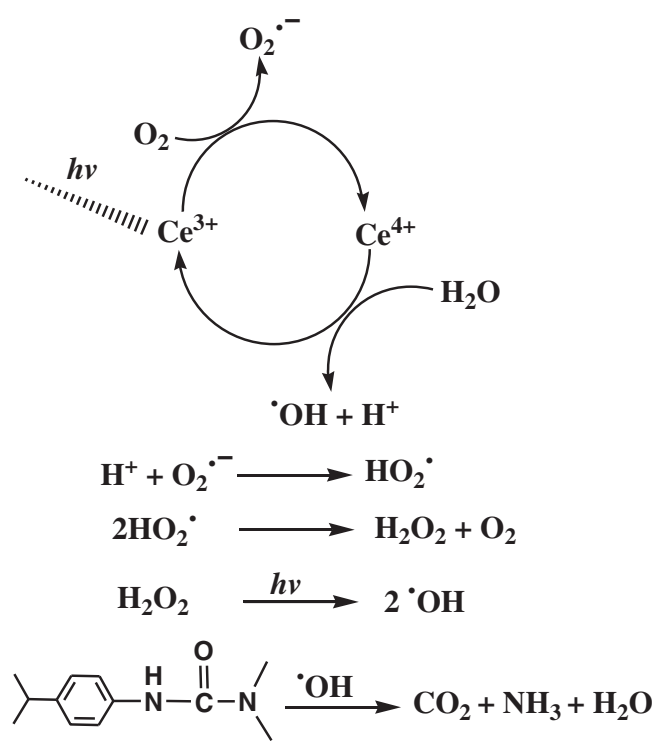

Scheme 1. Photocatalytic degradation pathway for isoproturon.

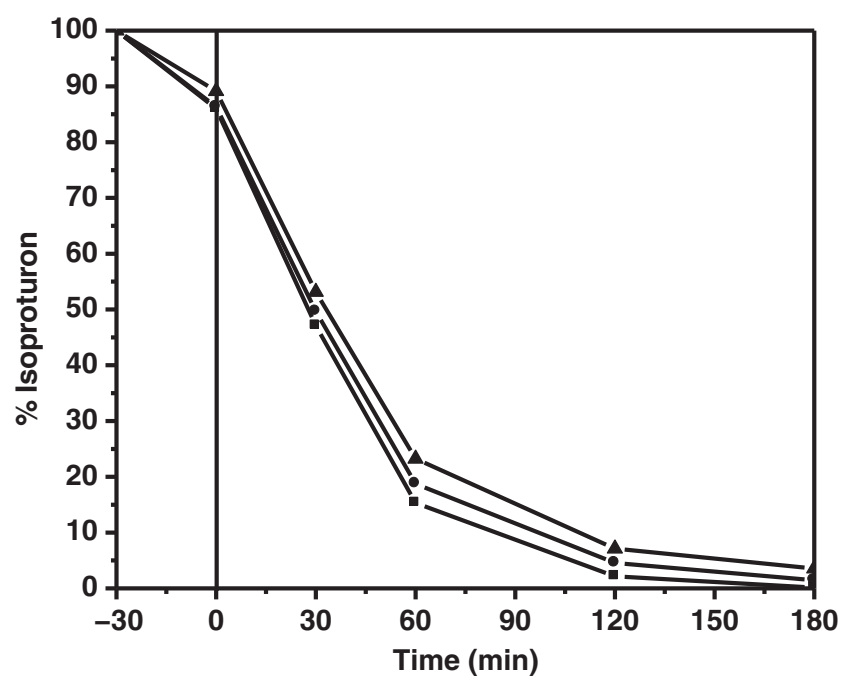

Figure 10. Recycling activity studies of 0.3 (wt $\%$ ) Ce-Al-SBA15 catalyst for the degradation of isoproturon: $(\square)$ Fresh, $(\bullet) 1$ st cycle and ( $\mathbf{\Lambda})$ 2nd cycle.

of bulk ceria is visualized in which cerium is in +3 and +4 oxidation states which are evidenced by XPS and UV-vis DRS techniques. This might be the reason for low activity at higher loadings of ceria. $\mathrm{Ce}^{3+}$ on irradiation becomes $\mathrm{Ce}^{4+}$ with a release of electron and this electron combines with oxygen forming a per-oxide that oxidizes the organic pollutant (scheme 1). From these, it is clearly understood that aluminum is playing a vital role in stabilizing the cerium species in +3 oxidation state resulting good photocatalytic activity. As $0.3 \mathrm{wt} \% \mathrm{Ce}-\mathrm{Al}-\mathrm{SBA}-15$ is showing better photoactivity, it is further tested for sustainability of phenol photo-degradation and the results obtained indicate that the catalyst can be reused without losing the photocatalytic activity (figure 10).

\section{Conclusions}

The present study described the preparation of Ce-modified SBA-15 photocatalyst and their photocatalytic activity for the degradation of isoproturon. The results illustrated that $0.3 \mathrm{wt} \% \mathrm{Ce}-\mathrm{Al}-\mathrm{SBA}-15$ was efficient catalyst for the photocatalytic degradation of isoproturon. The higher activity of 0.3 wt $\%$ Ce-Al-SBA-15 compared to bare $\mathrm{CeO}_{2}$-modified SBA-15 and this may be due to the presence of aluminum in Al-SBA-15 that stabilizes cerium in +3 oxidation states. From this study it is found that $\mathrm{Ce}$ at lower loadings over Al-SBA-15 exists in +3 oxidation state rather than +4 . The $\mathrm{Ce}^{3+} / \mathrm{Ce}^{4+}$ redox chemistry results in the degradation of isoproturon.

\section{Acknowledgement}

Anil Kumar Reddy and Subrahmanyam thank the Council of Scientific and Industrial Research (CSIR), New Delhi, for funding this work.

\section{References}

1. Chong M N, Jin B, Chow C W K and Saint C 2010 Water Res. 442997

2. Pelaez M, Nolan N T, Pillai S C, Seery M K, Falaras P, Kontos A G, Dunlop P S M, Hamilton J W J, Byrne J A, O'Shea K, Entezari M H and Dionysiou D D 2012 Appl. Catal. B 25331

3. Orlov A, Zhai Q Z and Klinowski J 2006 J. Mater. Sci. 412187

4. Sharma M V P, Durgakumari V and Subrahmanyam M 2008 Chemosphere 731562

5. Reddy J K, Lalitha K, Durgakumari V and Subrahmanyam M 2008 Catal. Lett. 121131

6. Mihai G D, Meynen V, Beyers E, Mertens M, Bilba N, Cool P and Vansant E F 2009 J. Porous Mater. 16109

7. Reddy J K, Srinivas B, Durgakumari V and Subrahmanyam M 2009a ChemCatChem 1492

8. Reddy J K, Durgakumari V, Subrahmanyam M and Sreedhar B 2009b Mater. Res. Bull. 441540

9. Sharma M V P, Durgakumari V and Subrahmanyam M $2010 \mathrm{~J}$. Hazard. Mater. 1751101

10. Anil Kumar Reddy P, Srinivas B, Pruthu K, Durgakumari V and Subrahmanyam M 2011 Mater. Res. Bull. 461766

11. Anil Kumar Reddy P, Srinivas B, Durgakumari V and Subrahmanyam M 2012 Toxicol. Environ. Chem. 94512

12. Li Y, Xia H, Fan F, Feng Z, Santen R A V, Hensen E J M and Li C 2008 Chem. Commun. 774

13. Lunawat P S, Kumar R and Gupta N M 2008 Catal. Lett. 121 226

14. Pradhan A C, Parida K M and Nand B 2011 Dalton Trans. 40 7348 
15. Yuan Q, Duan H H, Li L L, Li Z X, Duan W T, Zhang L S, Song W G and Yan C H 2010 Adv. Mater. 221475

16. Sheng X, Zhou Y, Duan Y, Zhang Y and Xue M 2011 J. Porous Mater. 18677

17. Sheng X, Zhou Y, Zhang Y, Duan Y and Xue M 2012 Catal. Lett. 142360

18. Pouretedal H R and Ahmadi M 2012 Int. Nano Lett. 21

19. Kim H Y, Lee H M and Henkelman G 2012 J. Am. Chem. Soc. 1341560

20. Buitrago R, Martínez J R, Albero J S, Escribano A S and Reinoso F R 2012 Catal. Today 18019

21. Li K, Tang X, Yi H, Ning P, Kang D and Wang C 2012 Chem. Eng. J. 19299
22. Zhao D, Feng J, Huo Q, Melosh N, Fredrickson G H, Chmelka B F and Stucky G D 1998 Science 279548

23. Mendoza A K M, Jácome M A C, Antonio J A T, Chávez C A, Salinas E L, López I C, Barrera M C, Escobar J, Navarrete J and Hernández I 2011 Appl. Catal. B 10614

24. Lakshmi K, Thrimurthulu G, Reddy B M, Muhler M and Grünert W 2011 Catal. Sci. Tech. 11645

25. Timofeeva M N, Jhung S H, Hwang Y K, Kim D K, Panchenko V N, Melgunov M S, Chesalov Y A and Chang J S 2007 Appl. Catal. A 3171

26. Wenqing J, Hong W and Ganzuo L I 2011 Rare Metals 5516

27. Beche E, Charvin P, Perarnau D, Abanades S and Flamant G 2008 Surf. Interface Anal. 40264 